DOI: $10.17516 / 1998-2836-0195$

УДК 54.057:542.943.7:547.316

\title{
Synthesis of Divanillin in the Presence \\ of Water Extract and Juice of Horseradish Root
}

\author{
Konstantin L. Kaygorodov, \\ Marina A. Smirnova and Valery E. Tarabanko* \\ Institute of Chemistry and Chemical Technology SB RAS \\ FRC "Krasnoyarsk Science Center SB RAS" \\ Krasnoyarsk, Russian Federation
}

Received 27.08.2020, received in revised form 31.08.2020, accepted 09.09.2020

Abstract. The divanillin synthesis by oxidative dimerization of vanillin in the presence of juice and water extracts of horseradish root (Armorácia rusticána), a more available and cheaper catalyst as compared with horseradish reactive peroxidase (HRP) was studied. The divanillin yield exceeds 90 mol. \% based on loaded vanillin. The peroxidase activity in juice and water extracts of horseradish root was estimated.

Keywords: Divanillin, vanillin, peroxidase catalysis, horseradish root, Armoracia rusticana.

Citation: Kaygorodov K.L., Smirnova M.A., Tarabanko V.E. Synthesis of divanillin in the presence of water extract and juice of horseradish root, J. Sib. Fed. Univ. Chem., 2020, 13(4), 525-533. DOI: 10.17516/1998-2836-0195

(C) Siberian Federal University. All rights reserved

This work is licensed under a Creative Commons Attribution-NonCommercial 4.0 International License (CC BY-NC 4.0).

* Corresponding author E-mail address: veta@icct.ru 


\title{
Синтез диванилина в присутствии водной вытяжки и сока корня хрена
}

\author{
К.Л. Кайгородов, М.А. Смирнова, В.Е. Тарабанько \\ Институт химии и химической технологии \\ ФИЦ «Красноярский научный изентр СО РАН» \\ Российская Федерация, Красноярск
}

\begin{abstract}
Аннотация. Изучены возможности синтеза диванилина окислительной димеризацией ванилина в присутствии сока и водных вытяжек корня хрена (Armoracia rusticana) - более доступного и дешевого катализатора по сравнению с реактивной пероксидазой хрена (HRP). Выход диванилина достигает более 90 мол. \% в расчете на загруженный ванилин. Определена активность пероксидазы в соке и водных вытяжках корня хрена.
\end{abstract}

Ключевые слова: диванилин, ванилин, катализ пероксидазой, корень хрена, Armoracia rusticana.

Цитирование: Кайгородов, К.Л. Синтез диванилина в присутствии водной вытяжки и сока корня хрена / К.Л. Кайгородов, М.А. Смирнова, В.Е. Тарабанько // Журн. Сиб. федер. ун-та. Химия, 2020. 13(4). С. $525-533$. DOI: $10.17516 / 1998-2836-0195$

В настоящее время все более актуальной проблемой становится замена ископаемого нефтехимического сырья возобновляемыми ресурсами $[1,2]$. Многие промышленные и перспективные химические продукты - ароматические соединения, основным возобновляемым источником которых может служить лигнин. Несмотря на большое количество исследований процессов выделения ароматических соединений из лигнина, единственным коммерчески производимым из него индивидуальным соединением является ванилин (4-гидрокси-3метоксибензальдегид) [3, 4].

Развитие эффективных методов получения ванилина из лигнина может способствовать появлению новых областей его потребления, таких как производство новых полимеров [5-8]. Одно из направлений синтеза полимеров может быть основано на использовании в качестве мономера нового бисфенола - диванилина (6,6'-дигидрокси - 5,5' - диметокси - (1,1'-бифенил) 3,3'-дикарбоксоальдегида, ДВ), продукта окислительной димеризации ванилина (рис. 1).

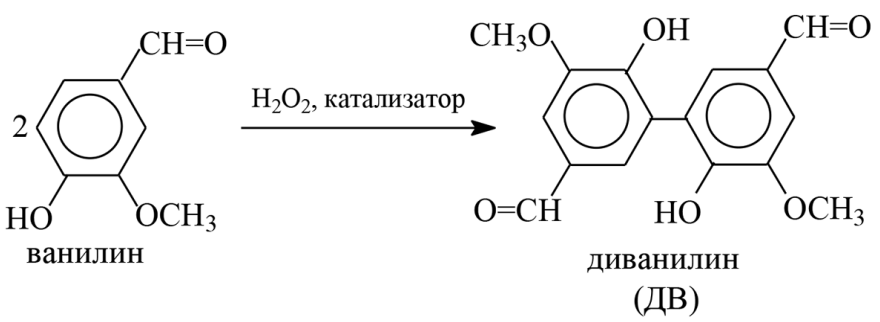

Рис. 1. Окислительная димеризация ванилина в диванилин

Fig. 1. Vanillin oxidative dimerization to divanillin 
Природный диванилин содержится в следовых количествах в стручках ванили, а также обнаруживается в продуктах ферментативного разложения древесины [9]. Это соединение может применяться в качестве ароматизатора молочных продуктов [10], входит в состав антиоксидантных композиций [11] и фоторезистов в микролитографии [12].

Известны методы окисления ванилина в диванилин неорганическими реагентами - сульфатом железа (II) и персульфатом натрия [13, 14], хлоридом железа (III) [15, 16], где выходы целевого продукта достигают 50-70 \%.

Основной способ повышения выхода диванилина окислением ванилина - использование ферментативных катализаторов. Крингс и Эспаран $[17,18]$ получали диванилин в присутствии ферментов грибов - пероксидазы чесночника обыкновенного (Marasmiuss corodonius), а также лакказ шампиньона двухспорового (Agaricus bisporus) и древесных грибов - мерипилуса гигантского (Meripilus giganteus), кориолопсиса (трутовика) Трога (Coriolopsis trogii). В качестве окислителя в случае лакказ выступал кислород, в случае пероксидаз - пероксид водорода, процессы окисления проводили в 5\%-ном этанольном растворе при $40-50{ }^{\circ} \mathrm{C}$ в течение 5 ч. Максимальный выход ДВ (95 \%) был достигнут при использовании лакказы кориолопсиса Трога (Coriolopsis trogii). В работе Ллевота с соавторами [19] описана димеризация ванилина под действием кислорода в присутствии лакказы трутовика радужного (Trametes versicolor) с выходом диванилина около 90 \%, однако процесс отличается большой длительностью (24 ч) и использованием водно-ацетоновых смесей в качестве растворителя. Все вышеупомянутые ферменты были реактивными (SigmaAldrich).

Пероксидаза хрена обыкновенного (Armoracia rusticana) (horseradish peroxidase - HRP) является широко известным ферментом, применяемым в качестве метки антител для иммуноферментного анализа, а также катализатором окисления фенольных соединений пероксидом водорода [20, 21].

Впервые синтез диванилина окислением ванилина пероксидом водорода в присутствии HRP в водном растворе провели Баумгартнер и Ньюком в 1972 г. с выходом порядка 80 \%. [22]. В работах $[23,24]$ для получения диванилина использована реактивная пероксидаза хрена с активностью $1000 \mathrm{ME} \mathrm{в} 100$ мл реакционного раствора, содержащего 1 г ванилина. Выход диванилина составлял 80-95 мас. \%.

Несмотря на доступность исходного сырья (корень хрена обыкновенного, Armoracia rusticana), реактивная пероксидаза хрена является дорогим реагентом (\$10000 за грамм, или $\$ 40$ за 1000 единиц активности пероксидазы, SigmaAldrich) [25].

Культивируемые в России сорта хрена содержат до 15 г пероксидазы на 1000 кг исходного сырья [26]. Строго говоря, корень хрена содержит несколько пероксидаз, и одна из индивидуальных пероксидаз, выделенная методами жидкостной хроматографии, имеет активность 26800 Ед/мг протеинов [27]. Активность пероксидазы в расчете на 1 г сырого корня, определенная в единицах оптической плотности при окислении гваякола, по данным [27], составляла 1220 единиц.

В работе [28] отмечается, что пероксидазная активность сырого корня хрена равна от 2,8 до $16,97 \mu$ моль/мин ${ }_{\Gamma}$ и содержание пероксидазы различается в разных частях растения (корень, боковые корни, черешки), произрастающего в Европе и Северной Америке. Емелин с соавторами [29] показали, что пероксидазная активность культивируемого в Центральной России сырого корня составляет от 15 до $40 \mu$ моль/мин×г. 
Сравнение данных [23-29] демонстрирует, что цена реактивной пероксидазы в качестве катализатора в процессе окисления ванилина в диванилин на два порядка превышает стоимость используемого ванилина. Это соотношение налагает существенные экономические ограничения на применение и развитие такого метода получения диванилина.

Поэтому цель настоящей работы заключается в исследовании возможностей получения диванилина из ванилина с использованием принципиально более дешевых и доступных водных вытяжек корня хрена и его сока в качестве источника пероксидазы.

\section{Экспериментальная часть}

В работе использовали ванилин фирмы SigmaAldrich, уксусную кислоту, перекись водорода, гидроксид натрия и соляную кислоту квалификации «хч». Корень хрена выкопан в сентябре 2019 г. и хранился в холодильнике при $10{ }^{\circ} \mathrm{C}$.

Приготовление сока хрена. Для выделения сока исходное сырье вымачивали в воде в течение суток, затем высушивали до удаления поверхностной влаги. Увеличение массы корней после вымачивания составляло 5-12 \%. Вымоченный корень тщательно измельчали. Из измельченного сырья выдавливали сок с помощью пресса, pН сока варьировался от 4,5 до 4,9.

Приготовление водной вытяжки корня хрена. Для получения водной вытяжки замоченные в течение суток корни гомогенизировали с четырехкратным по массе количеством фосфатного буферного раствора с рH 6,0, содержащего 12,14 г/л $\mathrm{NaH}_{2} \mathrm{PO}_{4}$ и 3,22 г/л $\mathrm{Na}_{2} \mathrm{HPO}_{4}$. Затем гомогенизат центрифугировали, отделяли центрифугат, а осадок подвергали дополнительной выжимке. Полученные светло-желтые растворы объединяли и отфильтровывали. Аналогично была получена вытяжка обработкой сырья дистиллированной водой.

Синтез диванилина. 1 г ванилина (6,6 ммоль) растворяли в 100 мл 10\%-ного водного раствора этанола или в воде при нагревании, затем раствор охлаждали до комнатной температуры, доводили кислотность раствора до $\mathrm{pH} 4$ раствором уксусной кислоты $(0,01 \mathrm{M})$, добавляли сок хрена или водную вытяжку корней хрена и 7,5 мл 3\%-ного раствора пероксида водорода (6,6 ммоль). Смесь перемешивали при комнатной температуре в течение 3-х часов. Образующийся серо-бежевый осадок отфильтровывали на воронке Бюхнера, промывали водой и сушили при $50{ }^{\circ} \mathrm{C}$. Очистку продукта проводили переосаждением соляной кислотой из водно-щелочного раствора. Целевой продукт представлял собой серый порошок, нерастворимый в воде.

ПМР-спектры полученного диванилина сняты в DMSO-d 6 при $25^{\circ} \mathrm{C}$, спектрометр Bruker Avance III 600 МГц, с привязкой к дейтериевому резонансу растворителя.

${ }^{1} \mathrm{H}$ ЯМР диванилина: $\delta$ м.д. 3,94 (6Н, $\mathrm{OCH}_{3}$ ), 7,43 (ароматические 2Н, Н-6), 7,44 (ароматические 2Н, Н-4), 9,82 (альдегидные 2Н, СНО).

Определение активности пероксидазы хрена. Определение активности пероксидазы проводили методом окисления гваякола в тетрагваякол [30]. Раствор гваякола готовили растворением 1,2414 г гваякола в 100 мл фосфатного буферного раствора $(\mathrm{pH}=6)$. Раствор 2 мМ пероксида водорода готовили растворением 15,6 мкл 30\%-ного $\mathrm{H}_{2} \mathrm{O}_{2}$ в 90 мл фосфатного буферного раствора $(\mathrm{pH}=6)$ и разбавляли до 100 мл водой. Для определения активности пероксидазы в кювету спектрофотометра вносили 2,8 мл фосфатного буферного раствора, 100 мкл раствора гваякола, 100 мкл 2мМ раствора пероксида водорода и 20 мкл раствора фермента (сока или водной вытяжки корня хрена). 
Полученный раствор немедленно фотометрировали при 470 нм относительно раствора сравнения, содержащего все перечисленные компоненты, за исключением $\mathrm{H}_{2} \mathrm{O}_{2}$, в течение 100 с. Измерение оптической плотности проводили в шести параллелях, активность рассчитывали по среднему значению.

Для определения устойчивости пероксидазы во время хранения при разных температурах образцы сока и экстрактов хранились при температурах: минус $18{ }^{\circ} \mathrm{C}, 4-5{ }^{\circ} \mathrm{C}, 23-28^{\circ} \mathrm{C}$.

\section{Результаты и обсуждение}

В табл. 1 представлены результаты определения активности пероксидазы в полученных соке и водных вытяжках. Активность пероксидазы в соке, наиболее концентрированном растворе фермента, составляет $60 \mu$ моль/мин $\times$ мл.

Более разбавленные вытяжки имеют примерно вчетверо меньшую активность, пропорционально разбавлению, 17 единиц. Активность пероксидазы в пересчете на массу исходного корня составила $68,3 \pm 2,6 \mu$ моль/мин×г, что близко к данным [29].

Важнейшим условием для использования полученных растворов в катализе является их стабильность. Растворы пероксидазы не теряют своей активности при замораживании, а также при хранении в течение суток при комнатной температуре. Сок наиболее стабилен и через неделю хранения в холодильнике при $4-5{ }^{\circ} \mathrm{C}$ практически не теряет своей активности. Потеря активности пероксидазы в водных вытяжках при хранении в холодильнике в течение недели невелика и составляет 10-12\% от исходной величины. При хранении в комнатных условиях в течение недели сок теряет около $10 \%$, а более разбавленные водные вытяжки - 20-25 \% исходной активности.

Полученные результаты показывают, что основная часть пероксидазы извлекается из корня уже при соотношении масс воды и корня 4:1 и получаемые вытяжки достаточно стабильны для их использования в катализе.

Таблица 1. Активность пероксидазы хрена (образцы: А - водный экстракт (1:4), Б - экстракт буферным раствором (1:4))

Table 1. The horseradish peroxidase activity (A - water extract (1:4), B - buffer solution extract (1:4))

\begin{tabular}{|c|c|c|c|c|c|c|c|}
\hline \multirow[b]{2}{*}{ Образец } & \multirow{2}{*}{$\begin{array}{c}\mathrm{T} \\
\text { хранения, } \\
{ }^{\circ} \mathrm{C}\end{array}$} & \multicolumn{6}{|c|}{ Активность пероксидазы, $\mu$ моль/мин×мл } \\
\hline & & $\begin{array}{c}\text { при } \\
\text { получении }\end{array}$ & 1 сут & 2 сут & 3 сут & 4 сут & 7 сут \\
\hline \multirow{3}{*}{ Сок } & -18 & $60,6 \pm 5,7$ & $60,6 \pm 5,7$ & $60,6 \pm 5,7$ & $60,6 \pm 5,7$ & $60,6 \pm 5,7$ & $60,6 \pm 5,7$ \\
\hline & $4-5$ & $60,6 \pm 5,7$ & $60,6 \pm 5,7$ & $60,6 \pm 5,7$ & $60,6 \pm 4,6$ & $60,5 \pm 4,8$ & $60,4 \pm 6,1$ \\
\hline & $23-28$ & $60,6 \pm 5,7$ & $60,6 \pm 5,7$ & $60,6 \pm 5,7$ & $59,9 \pm 6$ & $59,2 \pm 5,5$ & $55,7 \pm 6$ \\
\hline \multirow{3}{*}{ A } & -18 & $16,7 \pm 0,7$ & $16,7 \pm 0,7$ & $16,7 \pm 0,7$ & $16,7 \pm 0,7$ & $16,7 \pm 0,7$ & $16,7 \pm 0,7$ \\
\hline & $4-5$ & $16,7 \pm 0,7$ & $16,7 \pm 0,7$ & $16,6 \pm 0,9$ & $16,5 \pm 1$ & $16,3 \pm 0,9$ & $14,5 \pm 1$ \\
\hline & $23-28$ & $16,7 \pm 0,7$ & $16,7 \pm 0,7$ & $16,5 \pm 1$ & $16,4 \pm 0,9$ & $15,9 \pm 1,1$ & $13,7 \pm 1,5$ \\
\hline \multirow{3}{*}{ Б } & -18 & $17,1 \pm 0,4$ & $17,1 \pm 0,5$ & $17,1 \pm 0,5$ & $17,1 \pm 0,5$ & $17,1 \pm 0,6$ & $17,1 \pm 0,7$ \\
\hline & $4-5$ & $17,1 \pm 0,4$ & $17,1 \pm 0,5$ & $17,1 \pm 0,5$ & $16,7 \pm 0,8$ & $16,4 \pm 0,7$ & $15,3 \pm 0,9$ \\
\hline & $23-28$ & $17,1 \pm 0,4$ & $17,1 \pm 0,4$ & $16,7 \pm 0,6$ & $16,2 \pm 0,7$ & $15,4 \pm 0,9$ & $13,4 \pm 1,2$ \\
\hline
\end{tabular}


Таблица 2. Зависимость выхода неочищенного диванилина от количества добавленного сока хрена

Table 2. Influence of quantity of horseradish juice on the crude divanillin yield

\begin{tabular}{|c|c|c|c|}
\hline № & Объем сока, мл & Активность фермента, МЕ & $\begin{array}{c}\text { Выход ДВ, мол. \% } \\
\text { в расчете на ванилин }\end{array}$ \\
\hline 1 & 0,5 & 30,3 & 10,2 \\
\hline 2 & 2 & 121 & 32,5 \\
\hline 3 & 3,5 & 212 & 41,8 \\
\hline 4 & 5 & 303 & 97,1 \\
\hline 5 & 10 & 606 & 95,3 \\
\hline
\end{tabular}

Таблица 3. Зависимость выхода перекристаллизованного диванилина от количества добавленной водной вытяжки корней хрена

Table 3. Influence of quantity of water extract of horseradish root on the recrystallized divanillin yield

\begin{tabular}{|c|c|c|c|}
\hline № & Объем водной вытяжки, мл & Активность фермента, МЕ & $\begin{array}{c}\text { Выход ДВ, мол. \% в расчете } \\
\text { на ванилин }\end{array}$ \\
\hline 1 & 2 & 34,2 & 8,6 \\
\hline 2 & 8 & 137 & 31,7 \\
\hline 3 & 14 & 239 & 40,1 \\
\hline 4 & 20 & 342 & 94,5 \\
\hline 5 & 40 & 684 & 88,5 \\
\hline
\end{tabular}

В табл. 2 и 3 представлены результаты окисления ванилина в диванилин, катализируемого полученными препаратами пероксидазы. Выход диванилина определяется активностью пероксидазы в реакционной массе и проходит через максимум при активности фермента 300-350 ME на 100 мл рабочего раствора. Максимальный выход перекристаллизованного диванилина превышает $90 \%$ от стехиометрии.

\section{Заключение}

Полученные результаты демонстрируют, что сок и водные вытяжки корня хрена можно успешно использовать в методике препаративного синтеза диванилина. Выходы продукта в обоих случаях, как при использовании реактивной пероксидазы, так и сока или водных вытяжек корней, достигают 90-95 \%.

Сравнение данных [23-29] показывает, что цена реактивной HRP, необходимой для катализа процесса окисления ванилина в диванилин, на два порядка превышает стоимость реактивного ванилина и на три порядка - оптовые цены на ванилин. При цене корня хрена 1-10 долларов за килограмм замена реактивной пероксидазы на экстракт или сок корня хрена может на два - три порядка сократить расходы на катализатор.

Такое снижение затрат на реализацию методики синтеза диванилина позволит сделать ее более доступной для использования, например, в студенческих лабораторных практикумах по органической химии и биохимии $[23,31]$, а также в процессах препаративного синтеза диванилина.

$$
-530-
$$




\section{Благодарности / Acknowledgements}

Работа выполнена в рамках государственного задания Института химии и химической технологии СО РАН (проект АААА-А17-117021310219-4) с использованием оборудования Красноярского регионального центра коллективного пользования ФИЦ КНЦ СО РАН.

Авторы выражают признательность к.т.н. И.Г. Судаковой и к.Х.н. А.А. Кондрасенко за помощь в работе.

This work was carried out at the Institute of Chemistry and Chemical Technology, Siberian Branch, Russian Academy of Sciences within the framework of a state contract (Project AAAA-A17-117021310219-4) using the equipment of the Krasnoyarsk Regional Center of Research Equipment of Federal Research Center «Krasnoyarsk Science Center SB RAS».

The authors thank I.G. Sudakova and A.A. Kondrasenko for valuable assistance in this work.

\section{Список литературы / References}

1. Sheldon R.A. Green and Sustainable Manufacture of Chemicals from Biomass: State of The Art. Green Chemistry 2014. V. 16, P. 950-963.

2. Варфоломеев С.Д., Моисеев И.И., Мясоедов Б.Ф. Энергоносители из возобновляемого сырья. Химические аспекты. Вестник РАН 2009. Т. 79(7), С. 595-560. [Varfolomeev S.D., Moiseev I.I., Myasoedov B.F. Renewable energy sources. Chemical aspect. Vestnik RAS 2009. V. 79(7), P. 595-604. (In Russ.)].

3. Tuck C.O., Perez E., Horvath I.T., Sheldon R.A. Valorization of Biomass: Deriving More Value from Waste. Science 2012. V. 337, P. 695-700.

4. Rasmussen H., Sorensen H.R., Meyer A.S. Formation of degradation compounds from lignocellulosic biomass in the biorefinery: Sugar reaction mechanisms. Carbohydrate Research 2014. V. 385, P. 45-57.

5. Fache M., Darroman E., Besse V., Auvergne R., Caillol S., Boutevin B. Vanillin, a promising biobased building-block for monomer synthesis. Green Chemistry 2014. V. 16(4), P. 1987-1998.

6. Zhao S., Abu-Omar M.M. Renewable Thermoplastics Based on Lignin-Derived Polyphenols. Macromolecules 2017. V. 50 (9), P. 3573-3581.

7. Zhou J., Zhang H., Deng J., Wu Y. High Glass-Transition Temperature Acrylate Polymers Derived from Biomasses, Syringaldehyde, and Vanillin. Macromolecular Chemistry and Physics 2016. V. 217(21), P. 2402-2408.

8. Gang H., Lee D., Choi K.Y., Kim H.N., Ryu H., Lee D.S., Kim B.G. Development of High Performance Polyurethane Elastomers Using Vanillin-Based Green Polyol Chain Extender Originating from Lignocellulosic Biomass. ACS Sustainable Chemistry and Engineering 2017. V. 5, P. 4582-4588.

9. Lahtinen M., Kruus K., Boer H., Kemell M., Andberg M., Viikari L., Sipila J. The effect of lignin model compound structure on the rate of oxidation catalyzed by two different fungal laccases. Journal of Molecular Catalysis. B: Enzymatic 2009. V. 57(1-4), P. 204-210.

10. Patent 10310204 DE. Reiss I., Gatfield I.L., Krammer G., Clerc A., Kindel G. Verwendung von Divanillinals Aromastoff. Publ. Date 16.09.2004.

11. Patent 19950718 JP. Ikemoto T., Nakatsugawa H., Taira A., Koho K.T. Antioxidant composition. Publ. Date 18.07.1995.

$$
-531-
$$


12. Patent 5541033 US. Blakeney A.J., Medina A.N., Toukny A., Ferreira L., Tadros S. Selected O-Quinonediazide Sulfonic Esters of Phenolic Compounds and their Use In RadiationSensitive Compositions. Publ. Date 30.07.1996.

13. Elbs, K. Lerch, H. UberDehydrodivanillin. Journal fuer Praktische Chemie (Leipzig) 1916. V. 93, P. 1-9.

14. Fang Z., Nikafshar S., Hegg E.L., Nejad M. Biobased Divanillin as a Precursor for Formulating Biobased Epoxy Resin. ACS Sustainable Chemistry and Engineering 2020. V. 8(24), P. 9095-9103.

15. Kumar N., Pruthi V. Potential applications of ferulic acid from natural sources. Biotechnology Reports 2014. V. 4. P. 86-93.

16. Satpati S., Saha S.K., Suhasaria A., Banerjee P., Sukul D. Adsorption and Anti-corrosion Characteristics of Vanillin Schiff bases on Mild Steel in $1 \mathrm{M} \mathrm{HCl}$ : experimental and theoretical study. RSC Advances 2020. V. 10, P. 9258-9273.

17. Krings U., Esparan V., Berger R.G. The taste enhancer divanillin: a review on sources and enzymatic generation. Flavour and Fragrance Journal 2015. V. 30, P. 362-365.

18. Esparan V. Fungal Enzymes for the Production of Vanillin, Divanillin and Lignans. PhD Dissertation. 2015. Institute of Food Chemistry Leibniz University, Hannover, Germany. 112 p.

19. Llevot A., Grau E., Carlotti S., Grelier S., Cramail H. Renewable (semi)aromatic polyesters from symmetrical vanillin-based dimers. Polymer Chemistry 2015. V. 33(6), P. 6058-6066.

20. Kobayashi S., Makino A. Enzymatic Polymer Synthesis: An Opportunity for Green Polymer Chemistry. Chemical Reviews 2009. V. 109, P. 5288-5353.

21. Morsi R., Bilal M., Iqbal H.M.N., Ashraf S.S. Laccases and peroxidases: The smart, greener and futuristic biocatalytic tools to mitigate recalcitrant emerging pollutants. Science of Total Environment. 2020. V. 714, P. 136572. https://doi.org/10.1016/j.scitotenv.2020.136572.

22. Baumgartner J., Neukom, H. Enzymatische Oxidation von Vanillin. Chimia. 1972. P. 366-368.

23. Nishimura R.T., Giamanco C.H., Vosburg D.A. Green, Enzimatic Synthesis of Divanillin and Diapocynin for the Organic, Biochemistry, or Advanced General Chemistry Laboratory. Journal of Chemical Education 2010. V. 87(5), P. 526-527.

24. Amarasekara A.S., Wiredu B., Razzaq A. Vanillin based polymers: I. An electrochemical route to polyvanillin. Green Chemistry 2012. V. 14(4), P. 2395-2397.

25. Biochemical organic compounds and diagnostic reagents. Каталог фирмы "Sigma" Chemical Company. USA.

26. Капизова А.М., Садомцева О.С., Шакирова В.В. Определение ферментов антиоксидантов, содержащихся в корне хрена, выращенного в Астраханской области в летне-осенний период. Научный журнал КубГАУ 2016. Т. 118(4), С. 1-4. [Kapizova A.M, Sadomtseva O.S., Shakirova V.V. Determination of antioxidant enzymes contained in horseradish root grown in the Astrakhan region in the summer-autumn period. Nauchniy zhurnal KubGAU 2016. V. 118(4), P. 1-4. (In Russ.)].

27. Mohamed S.A., Abulnaja K.O., Ads A.S., Khan J.A., Kumosani T.A. Characterisation of an anionic peroxidase from horseradish cv. Balady. Food Chemistry 2011. V. 128, P. 725-730.

28. Kushad M.M., Guidera M., Bratsch A.D. Distribution of horseradish peroxydase activity in horseradish plants. Hort Science 1999. V. 34(1), P. 127-129.

29. Емелин Ю.М., Власов Н.А., Новиков Б.В., Середа А.Д., Волохов Д.С., Фугина Л.С., Середа С.В. Активность пероксидазы в различных органах растений хрена и других сельскохо- 
зяйственных культур. Сельскохозяйственная биология 2003. Т. 38(3), С. 100-103. [Emelin Yu.M., Vlasov N.A., Novikov B.V., Sereda A.D., Volokhov D.S., Fugina L.S., Sereda S.V. Peroxidase activity in various organs of horseradish plants and other crops. Agricultural Biology 2003. V. 38(3), P. 100103. (InRuss.)].

30. Vermelho B.A., Couri, S. Methods to determine enzymatic activity. 2013. BenthamSciencePublishers. P. 30-34. https://doi.org/10.2174/97816080530011130101.

31. Физиологические и биохимические методы анализа растений: Практикум. Чупахина Г.Н. Калининград, 2000. 59 с. [Physiological and biochemical methods of plant analysis: Practical work. Chupakhina G.N. Kaliningrad, 2000. 59 p. (In Russ.)]. 